\title{
A novel role for apatinib in enhancing radiosensitivity in non- small cell lung cancer cells by suppressing the AKT and ERK pathways
}

\author{
Lin Li ${ }^{1,2}$, Yuexian $\mathbf{L i}^{2}$, Huawei Zou ${ }^{\text {Corresp. } 2}$ \\ ${ }^{1}$ The First Oncology Department, The Fourth Hospital of China Medical University, Shenyang, Liaoning, China \\ Department of Oncology, Shengjing Hospital of China Medical University, Shenyang, Liaoning, China \\ Corresponding Author: Huawei Zou \\ Email address: Zouhw999@163.com
}

Background. Radioresistance is still the major cause of radiotherapy failure and poor prognosis in patients with non-small cell lung cancer (NSCLC). Apatinib (AP) is a highly selective inhibitor of vascular endothelial growth factor receptor 2 (VEGFR2). Whether and how AP affects radiosensitivity in NSCLC remains unknown. The present study aimed to explore the radiosensitization effect of AP in NSCLC and its underlying mechanism as a radiosensitizer.

Methods. The NSCLC cell lines A549 and LK2 were treated with AP, ionizing radiation (IR), or both AP and IR. Expression of VEGFR2 was analyzed by western blot and RT-PCR. Cell proliferation was measured using CCK-8 and colony formation assays. Apoptosis and cell cycle distribution in NSCLC cells were analyzed by flow cytometry. Nuclear phosphorylated histone H2AX foci immunofluorescence staining was performed to evaluate the efficacy of the combination treatment. Western blot was used to explore the potential mechanisms of action.

Results. AP inhibited cell proliferation in a dose- and time-dependent manner. Flow cytometry analysis indicated that AP significantly increased radiation-induced apoptosis. Colony formation assays revealed that AP enhanced the radiosensitivity of NSCLC cells. AP strongly restored radiosensitivity by increasing IR-induced G2/M phase arrest. AP effectively inhibited repair of radiation-induced DNA double-strand breaks. Western blot analysis showed that AP enhanced radiosensiti vity by downregulating AKT and extracellular signal-regulated kinase (ERK) signaling.

Conclusion. Our findings suggest that AP may enhance radiosensitivity in NSCLC cells by blocking AKT and ERK signaling. Therefore, AP may be a potential clinical radiotherapy synergist and a novel smallmolecule radiosensitizer in NSCLC. Our study fills a gap in the field of anti-angiogenic drugs and radiosensitivity. 
2 A novel role for apatinib in enhancing radiosensitivity

3 in non-small cell lung cancer cells by suppressing the 4 AKT and ERK pathways

5

7

Lin $\mathrm{Li}^{1,2}$, Yuexian $\mathrm{Li}^{1}$, Huawei Zou ${ }^{1}$

${ }^{1}$ Department of Oncology, Shengjing Hospital of China Medical University, Shenyang, China.

${ }^{2}$ The First Oncology Department, The Fourth Hospital of China Medical University, Shenyang, China.

Corresponding Author: Huawei Zou ${ }^{1}$

No.39 Huaxiang Road, Tiexi District Shenyang, Liaoning Zip code 1100022, China Email address: Zouhw999@163.com

\section{Abstract}

Background. Radioresistance is still the major cause of radiotherapy failure and poor prognosis in patients with non-small cell lung cancer (NSCLC). Apatinib (AP) is a highly selective inhibitor of vascular endothelial growth factor receptor 2 (VEGFR2). Whether and how AP affects radiosensitivity in NSCLC remains unknown. The present study aimed to explore the radiosensitization effect of AP in NSCLC and its underlying mechanism as a radiosensitizer. Methods. The NSCLC cell lines A549 and LK2 were treated with AP, ionizing radiation (IR), or both AP and IR. Expression of VEGFR2 was analyzed by western blot and RT-PCR. Cell proliferation was measured using CCK-8 and colony formation assays. Apoptosis and cell cycle distribution in NSCLC cells were analyzed by flow cytometry. Nuclear phosphorylated histone $\mathrm{H} 2 \mathrm{AX}$ foci immunofluorescence staining was performed to evaluate the efficacy of the combination treatment. Western blot was used to explore the potential mechanisms of action. Results. AP inhibited cell proliferation in a dose- and time-dependent manner. Flow cytometry analysis indicated that AP significantly increased radiation-induced apoptosis. Colony formation assays revealed that AP enhanced the radiosensitivity of NSCLC cells. AP strongly restored radiosensitivity by increasing IR-induced G2/M phase arrest. AP effectively inhibited repair of radiation-induced DNA double-strand breaks. Western blot analysis showed that AP enhanced radiosensitivity by downregulating AKT and extracellular signal-regulated kinase (ERK) signaling. 
38

39

40

41

42

43

44

45

46

47

48

49

50

51

52

53

54

55

56

57

58

59

60

61

62

63

64

65

66

67

68

69

70

71

72

73

74

75

76

77

Conclusion. Our findings suggest that AP may enhance radiosensitivity in NSCLC cells by blocking AKT and ERK signaling. Therefore, AP may be a potential clinical radiotherapy synergist and a novel small-molecule radiosensitizer in NSCLC. Our study fills a gap in the field of anti-angiogenic drugs and radiosensitivity.

\section{Introduction}

Lung cancer is the leading cause of morbidity and mortality worldwide, and the incidence and prevalence of lung cancer is increasing(Sung et al. 2021). Approximately $85 \%$ of lung cancer patients are diagnosed with non-small cell lung cancer (NSCLC), most of whom are diagnosed at advanced stages. Currently, radiotherapy remains the main therapeutic approach for advanced NSCLC. Although many strategies have been developed to improve the efficacy of radiotherapy for NSCLC, many patients still experience tumor relapse and fatal distant metastasis caused by radioresistance. Therefore, current research focuses on enhancing the radiosensitivity(Kim et al. 2021; Lewis et al. 2021; Seidlitz et al. 2020; Wrona et al. 2021; Xiong et al. 2021). At present, the major types of radiosensitizers include electrophilic radiosensitizers, biological reducers, chemotherapeutic drugs, and natural products(Schrank et al. 2018). Although many radiosensitizers have been studied to improve the radiosensitivity of tumors, their clinical application has not been satisfactory(Ohri et al. 2016). The role of small-molecule targeted drugs in enhancing radiosensitivity in NSCLC is unclear.

Angiogenesis is an essential step in the progression of various types of solid tumors(Chen et al. 2017; Hanahan \& Weinberg 2011). The vascular endothelial growth factor (VEGF) plays a critical role in angiogenesis(Jain 2005; Jain 2013). VEGF receptors (VEGFRs) include three protein tyrosine kinases: VEGFR1, VEGFR2, and VEGFR3. VEGFR2 is the main functional tyrosine kinase membrane receptor of VEGF in endothelial cells, playing pivotal roles in transducing VEGF signals and stimulating phosphorylation of extracellular signal-regulated kinase (ERK) through a protein kinase C-dependent pathway. In a variety of malignancies, including NSCLC, the overexpression of VEGF and VEGFR is correlated with increased tumor growth, microvessel density, proliferation, tumor metastasis potential, and poor prognosis. Therefore, inhibiting VEGFR signaling is an attractive therapeutic option in combination with other antitumor regimens in clinical practice(Han et al. 2019; Peng et al. 2017). Apatinib (AP), a small-molecule inhibitor of VEGFR2, can prevent VEGF-induced phosphorylation of VEGFR2 and subsequent downstream signal transduction, thereby inhibiting the migration and proliferation of endothelial cells stimulated by VEGF. It also inhibits tumor angiogenesis caused by VEGF signaling. AP has been shown to inhibit VEGF-mediated intracellular neovascularization signals in vivo, thereby promoting tumor cell apoptosis and inhibiting cell proliferation. AP alone or in combination with chemotherapy drugs inhibits the growth of several human tumors by inhibiting angiogenesis(Chen et al. 2018; Liu et al. 2017; Procaccio et al. 2019). AP has also been reported to improve radiosensitivity of several human tumors(Hu et al. 2018; Hu et al. 2019; Liang et al. 2020; Liao et al. 2019; Zhao et al. 2017a). Yet, whether AP can enhance the radiosensitivity of lung cancer remains to be further explored. 
78 We hypothesized that AP may play a novel role in the radiosensitivity of NSCLC cells.

79 Therefore, in the present study, we investigated whether AP enhances radiosensitivity and 80 explored the underlying mechanisms of radiosensitization in NSCLC cells. The results may 81 provide a theoretical basis for the clinical combination of radiation and AP.

82

\section{Materials \& Methods}

\section{AP preparation, cell culture, and ionizing radiation (IR) protocol}

85 AP was obtained from the Jiangsu Hengrui Medicine Company (Jiangsu, China). AP was

86 dissolved in $100 \%$ dimethyl sulfoxide (DMSO) as a $100 \mathrm{mM}$ stock solution and diluted with

87 RPMI-1640 medium to the desired concentration.

88 Cells were cultured as previously described in Yuexian Li (2021 Jan 18)(Li et al. 2021).

89 Specifically, the normal mammary epithelial cell line HBEC and four human NSCLC cell lines, 90 A549, H460, H226, and H522, were purchased from the American Type Culture Collection 91 (Manassas, VA, USA). LK2 cells were obtained from the Cell Bank of the Chinese Academy 92 (Shanghai, China). All cells were cultured in RPMI-1640 medium (Sigma-Aldrich, Darmstadt, 93 Germany) and supplemented with 10\% fetal bovine serum (Clark Bioscience, Richmond, VA, 94 USA) and 1\% penicillin/streptomycin (Sigma-Aldrich) in a humidified incubator at $37^{\circ} \mathrm{C}$ in $5 \%$ $95 \mathrm{CO}_{2}$. A 6-MeV X-ray medical linear accelerator (Elekta Synergy, Elekta, Stockholm, Sweden) was used to irradiate the cells at a dose rate of $300 \mathrm{cGy} / \mathrm{min}$ (dose: 0 to $8 \mathrm{~Gy}$ ) at room temperature.

98

99

100

101

102

103

104

105

106

107

108

109

110

111

112

113

114

115

116

\section{RNA extraction, reverse transcription, and qRT-PCR}

RNA extraction, reverse transcription, and qRT-PCR were conducted as previously described in Yuexian Li(2021 Jan 18)(Li et al. 2021). Specifically, total RNA was extracted from cells using the TRIzol ${ }^{\text {TM }}$ Plus Kit (Takara, Osaka, Japan) according to the manufacturer's instructions. cDNA was synthesized with total RNA $(1 \mu \mathrm{g})$ using a real-time PCR system (Life Technologies, Carlsbad, CA, USA), and qRT-PCR was performed with total cDNA (100 ng) using an Applied Biosystems 7500 Real-Time PCR system with SYBR ${ }^{\mathrm{TM}}$ Green Master Mix (Takara, Osaka, Japan). The relative expression of $V E G F R 2$ was determined using the $2^{-\triangle \triangle \mathrm{Ct}}$ method after normalization to GAPDH expression. The primers for VEGFR2 were as follows: forward, 5'GTGATCGGAAATGACACTGGAG-3' and reverse, 5'-CATGTTGGTCACTAACAGAAGCA$3^{\prime}$.

\section{Flow cytometric analysis}

Apoptosis and cell cycle status were conducted as previously described in Yuexian Li (2021 Jan 18)(Li et al. 2021). Specifically, apoptosis was measured using the FITC Annexin V Apoptosis Detection Kit (BD Pharmingen, San Diego, CA, USA) according to the manufacturer's instructions. Approximately $10 \times 10^{5}$ A549 cells or $15 \times 10^{5} \mathrm{LK} 2$ cells were seeded into 6-well plates and irradiated with 0 or 8 Gy the next day, cultured for another $48 \mathrm{~h}$, and then incubated 
117 with FITC-labeled annexin V and propidium iodide (PI) at room temperature in the dark for 15

118 min.

119 Cell cycle analysis was performed using $50 \mu \mathrm{g} / \mathrm{mL}$ PI and $100 \mu \mathrm{g} / \mathrm{mL}$ DNase-free RNase A

120 (Solarbio, Beijing, China). $40 \times 10^{5} \mathrm{~A} 549$ cells or $60 \times 10^{5} \mathrm{LK} 2$ cells were seeded into $25 \mathrm{~cm}^{2}$

121 Cell Culture Flasks. Twenty-four hours post-irradiation, cells were harvested with trypsin,

122 washed with phosphate-buffered saline, and fixed in $70 \%$ ice-cold ethanol at $4^{\circ} \mathrm{C}$ for $12 \mathrm{~h}$. After

123 washing, the cell pellet was resuspended in PI staining buffer and incubated at $37^{\circ} \mathrm{C}$ for $30 \mathrm{~min}$

124 in the dark. Apoptosis and cell cycle status were analyzed by flow cytometry (BD FACSCalibur,

125 BD Biosciences, San Jose, CA, USA).

126

127

\section{Cell proliferation and colony formation assay}

128

Cells were seeded into plates with 96 wells at 2000 A549 cells or 4000 LK2 cells per well. After

129 exposure to a single dose of radiation ( $8 \mathrm{~Gy}$ ), cells were incubated for $24,48,72$, or $96 \mathrm{~h}$, at

130 which point Cell Counting Kit-8 (Beyotime, Shanghai, China) was used to determine cell viability. Absorbance was measured using a microplate reader (BioTek, Winooski, VT, USA) at a wavelength of $450 \mathrm{~nm}$. The $\mathrm{IC}_{50}$ value of each cell line was calculated using the GraphPad Prism 7 software (La Jolla, CA, USA). 18)(Li et al. 2021). Specifically, 200 cells were seeded into 6-well plates and irradiated (0, 2, 4, 6 , and 8 Gy) the next day. Two weeks later, the cells were fixed in $4 \%$ paraformaldehyde and stained with $0.1 \%$ crystal violet, and the number of colonies per dish was counted. The plating efficiency and surviving fraction were calculated as previously described(Sun et al. 2019).

139

\section{Immunofluorescence detection of phosphorylated histone $\mathrm{H} 2 \mathrm{AX}(\gamma \mathrm{H} 2 \mathrm{AX})$}

The immunofluorescence assay was conducted as previously described in Yuexian Li (2021 Jan 18)(Li et al. 2021). Specifically, cells growing on glass coverslips were exposed to 0 or $8 \mathrm{~Gy}$ irradiation. Four hours later, the cells were fixed in 4\% paraformaldehyde and incubated with the primary phospho- $\gamma \mathrm{H} 2 \mathrm{AX}$ antibody (Ser139, Abcam, San Diego, CA, USA) and a secondary antibody conjugated to $\mathrm{Cy} 3$ (Beyotime) according to the manufacturer's protocol. Staining was analyzed using a confocal laser scanning microscope (Nikon, Tokyo, Japan).

\section{Protein extraction and western blotting}


149 Protein extraction and western blotting were conducted as previously described in 150 Yuexian Li (2021 Jan 18)(Li et al. 2021). Specifically, total protein was extracted from 151 cells using radioimmunoprecipitation assay lysis buffer (Beyotime). Total protein 152 concentrations were quantified using a bicinchoninic acid assay kit (Beyotime). Equal 153 amounts $(30 \mu \mathrm{g})$ of proteins were boiled at $100^{\circ} \mathrm{C}$, separated by sodium dodecyl sulfate154 polyacrylamide gel electrophoresis, and transferred onto polyvinylidene fluoride 155 membranes (Millipore, Bedford, MA, USA). The membranes were blocked with 5\% $156(\mathrm{w} / \mathrm{v})$ skim milk at room temperature and immunoblotted overnight at $4{ }^{\circ} \mathrm{C}$ with primary 157 antibodies against GAPDH (Proteintech; Chicago, IL, USA, 60004-1-Ig), VEGFR2 158 (Absin; Shanghai, China, abs131800), and AKT (Cell Signaling Technology; Beverly, 159 MA, USA, \#4685), phospho-AKT (Cell Signaling Technology; Beverly, MA, USA, \#4060), ERK (Cell Signaling Technology; Beverly, MA, USA, \#4695), and phosphoERK (Cell Signaling Technology; Beverly, MA, USA, \#4370). The membranes were then incubated with the appropriate horseradish peroxidase-conjugated secondary antibodies (HRP-conjugated goat anti-mouse IgG, Zsgb Bio, ZB-2305; HRP-conjugated goat anti-rabbit IgG, Zsgb Bio, ZB-2301).

165

166

167

168

\section{Statistical analysis}

The experimental data were calculated as the mean \pm standard deviation of at least three independent experiments. The data were analyzed, and statistical graphs were created using GraphPad Prism 7. Differences between groups were analyzed using the Student's $t$-test, oneway analysis, and two-way ANOVA. Statistically significant differences were determined at $\mathrm{p}<$ $0.05(*),<0.01(* *)$, or $<0.001(* * *)$.

(1)

\section{Results}

\section{Expression of VEFGR2 in NSCLC cells}

The A549, H522, H460, LK2, and H226 cell lines were evaluated for VEGFR2 expression by western blotting and qRT-PCR (Fig. 1A and 1B). VEGFR2 protein expression differed among the five NSCLC cell lines. A549 and LK2 cells were selected for further study based on their expression of VEGFR2.

To examine the effects of AP on NSCLC cell growth, the cytotoxicity of AP against NSCLC cell lines was determined using the CCK8 assay. The human lung cancer cell lines A549 and LK2 were cultivated with a series of increasing concentrations of AP $(0,5,10,20,40$, and $80 \mu \mathrm{mol} / \mathrm{L})$ for $24 \mathrm{~h}, 48 \mathrm{~h}$, and $72 \mathrm{~h}$. AP significantly inhibited the proliferation of A549 and LK2 cells in vitro in a dose- and time-dependent manner (Fig. $1 \mathrm{C}$ and $1 \mathrm{E}$ ). After calculation, the $\mathrm{IC}_{50}$ doses of AP after treatment for $24 \mathrm{~h}$ in LK2 cells and A549 cells were $30.73 \mu \mathrm{mol} / \mathrm{L}$ and $17.61 \mu \mathrm{mol} / \mathrm{L}$, 
188

189

190

191

192

193

194

195

196

197

198

199

200

201

202

203

204

205

206

207

208

209

210

211

212

213

214

215

216

217

218

219

220

221

222

223

224

225

226

227

respectively (Fig. $1 \mathrm{D}$ and $1 \mathrm{~F}$ ). We chose the $\mathrm{IC}_{20}$ concentration at $24 \mathrm{~h}$ in subsequent experiments.

\section{AP promoted cell death and enhanced radiosensitivity in NSCLC cells}

To explore the efficacy of AP in combination with radiotherapy, the CCK8 assay was conducted to determine whether the inhibitory effect of IR was enhanced by AP. LK2 and A549 cells were pretreated with AP or DMSO for 24, 48, 72, or $96 \mathrm{~h}$ and exposed to $8 \mathrm{~Gy}$ irradiation. Compared to IR alone, cell growth was remarkably suppressed in the cells pretreated with AP before IR at all of the time points examined, although this effect was particularly visible at $96 \mathrm{~h}$. In addition, cells treated with both AP and IR had less proliferation than cells treated with IR or AP alone (Fig. 2A and 2 B). These results suggest that AP suppresses the proliferation of NSCLC cells in vitro and enhances the radiosensitivity of NSCLC cells.

To further confirm the radiosensitivity effects of AP, a colony formation assay was performed. The results revealed that treatment with AP plus IR significantly reduced the survival rate in both NSCLC cell lines compared with cells treated with AP or IR alone. The sensitivity enhancement ratios (SERs) were 1.95 and 2.15 in LK2 and A549 cells, respectively (Table 1). These data suggest that AP sensitizes NSCLC cell lines to IR in vitro.

\section{AP and radiation combination therapy affected apoptosis and cell cycle progression of NSCLC cells}

Flow cytometry was used to determine whether AP could induce NSCLC cell apoptosis and enhance the radiosensitivity of A549 and LK2 cells. Annexin V and PI staining were used to detect the percentage of cell death in A549 and LK2 cells treated with AP after $48 \mathrm{~h}$ with or without IR. The percentages of apoptotic A549 and LK2 cells were significantly higher in cells treated with AP than in control cells. Further, AP combined with IR remarkably enhanced apoptosis compared with control cells and cells treated with either AP or IR (Fig. 3A). Taken together, these results demonstrate that AP enhances radiation-induced cell apoptosis.

To further investigate the effect of AP in NSCLC cells after IR, the cell cycle distribution after treatment was analyzed by flow cytometry. Radiation-induced DNA damage triggers G1 or G2 cell cycle arrest, allowing cells to repair DNA damage. AP has been reported to hamper cell cycle progression, leading to G0/G1 or G2/M arrest. As shown in Fig. 3B, in A549 cells, radiation-induced DNA damage triggered G1 and G2 arrest, and AP induced G2/M arrest. Cell cycle arrest was significantly enhanced by IR. Cell cycle analysis showed that A549 cells treated with both AP and IR had the greatest increase in the G2/M phase proportion, and this proportion was significantly higher than that of control cells $(p<0.01)$. The same effect was observed in the LK2 cells. Therefore, AP improves the efficiency of IR by causing G2/M arrest. These results indicate that AP enhances radiation-induced apoptosis and G2/M arrest.

\section{Radiosensitization by AP was associated with delayed DNA-double-strand break (DSB) repair}


228 IR induces DNA-DSBs and triggers DNA damage repair responses. The ability to repair DNA229 DSBs reflects the radiosensitivity of cells. $\gamma$-H2AX was used to monitor the presence of DNA230 DSBs to determine whether AP pretreatment enhances radiation-induced DNA damage and 231 interferes with DNA damage repair. Immunofluorescence staining was used to detect the number 232 of $\gamma$-H2AX-positive nuclei. There were notably more $\gamma$-H2AX-positive cells among cells treated with both AP and IR than in cells treated with IR alone at $4 \mathrm{~h}$ post-IR (Fig. 4A and $4 \mathrm{~B}$ ), which reflected inefficient repair of DSBs in cells treated with the combination. These results indicate that AP significantly increases the number of $\gamma-\mathrm{H} 2 \mathrm{AX}$-positive nuclei and suppresses repair of

237 radiation-induced DNA-DSBs after IR.

\section{AP blocks AKT and ERK signaling to sensitize lung cancer cells to radiation}

240

The AKT and ERK pathways are known to be activated by IR; this activation might play a role in radioresistance in NSCLC cells. Our previous results showed that downregulation of the AKT and ERK signaling enhanced radiosensitivity(Sun et al. 2019). In order to determine the potential molecular mechanisms by which AP exerts enhanced antitumor effects and regulates radiosensitivity, we examined the phosphorylation of AKT and ERK by western blotting. The results showed that phosphorylated AKT (p-AKT) and ERK (p-ERK) were reduced after AP treatment in both A549 and LK2 cells. The combination of AP and radiation significantly decreased the activities of AKT and ERK in A549 and LK2 cells (Fig. 5A and 5B). In summary, these data indicate that AP enhances radiosensitivity by decreasing AKT and ERK signaling in NSCLC cells.

251

252

253

254

255

256

257

258

259

260

261

262

263

264

265

266

267

\section{Discussion}

Radiotherapy is still one of the most effective measures for the treatment of NSCLC. However, radioresistance contributes to treatment failure. Radiosensitizers have been widely studied in an effort to improve the effectiveness of radiotherapy, but the results have not been satisfactory for NSCLC(Tian et al. 2011). Clinically, the anti-angiogenic drug endostatin exerts a radiosensitizing effect in NSCLC by inhibiting VEGFR2 expression(Liu et al. 2016). Another report suggested that the anti-angiogenic drug bevacizumab enhanced the cytotoxicity of antitumor drugs through the VEGF/VEGFR2 pathway in colon cancer(Liu et al. 2018). Previous studies have shown that VEGF plays a critical role in angiogenesis in lung cancer, thereby promoting lung cancer progression. Additionally, VEGF overexpression increases the radioresistance of NSCLC, which contributes to disease progression and poor prognosis(Cascone et al. 2017; Chatterjee et al. 2013). VEGFR2 is the main functional tyrosine kinase membrane receptor of VEGF in endothelial cells and plays a pivotal role in transducing VEGF signals. When VEGF is activated, VEGFR2 phosphorylation induces endothelial cell proliferation and migration(Longo \& Gasparini 2007). VEGFR2 is differentially expressed in NSCLC. A tumor cell-autonomous VEGF-VEGFR2 feed-forward loop provides signal amplification required for the establishment of fully angiogenic tumors in lung cancer(Chatterjee et al. 2013). In addition, autocrine regulation of tumor radioresistance occurs through the VEGF-VEGFR2 
268

269

270

271

272

273

274

275

276

277

278

279

280

281

282

283

284

285

286

287

288

289

290

291

292

293

294

295

296

297

298

299

300

301

302

303

304

305

306

307

interaction(Knizetova et al. 2008). AP is an oral small-molecule inhibitor of VEGFR2 that can suppress cell proliferation in a variety of tumors(Feng et al. 2018; Hu et al. 2014; Lu et al. 2017). It has been reported that AP enhances radiosensitivity by inhibiting proliferation in hepatocellular carcinoma and metastatic prostate cancer(Liao et al. 2019; Zhao et al. 2017b). In this study, we focused on whether AP could be utilized as a novel target drug to enhance radiosensitivity in NSCLC cells and examined the potential mechanism.

It is well known that radiation inhibits tumor growth and promotes apoptosis. Radiation-resistant cancer cells are more capable of surviving radiation and have high proliferative potential. Radioresistant cells may avoid radiation damage by suppressing apoptosis, causing cell cycle arrest, and promoting DNA repair, all of which are related to cancer cell pro-survival signaling pathways following radiation treatment(Hein et al. 2014). Our results demonstrated that AP significantly inhibited NSCLC cell proliferation. Moreover, we also observed that the proliferation ability of NSCLC cells was reduced more significantly by AP combined with IR than by either AP or IR alone. In cells treated with both AP and IR, growth inhibition increased as the concentration of AP or the treatment time increased, indicating that this combination treatment works in a dose- and time-dependent manner. To better understand this phenomenon, we performed colony formation assays, which confirmed the radiosensitivity effects of AP. The results revealed that treatment with AP plus IR significantly reduced the survival rate in both NSCLC cell lines compared to treatment with AP or IR alone. The SERs were 1.95 and 2.15 in LK2 and A549 cells, respectively. Collectively, these results led us to postulate that AP might enhance radiosensitivity by decreasing the proliferation and survival abilities of NSCLC cells after IR. Apoptosis is also a key effector mechanism of IR(Hanahan \& Weinberg 2011), and radiotherapy induces and triggers apoptotic cell death. Previous studies have also reported that radiosensitivity may be associated with apoptosis and suppression of angiogenesis in lung cancer cells(Han et al. 2017). Furthermore, a recent study has shown that deregulation of BCL-2 family proteins may overcome radioresistance in NSCLC(Wieczorek et al. 2017). Previous studies showed that AP could promote apoptosis by upregulating the expression of BAX proteins and other pro-apoptotic proteins and downregulating the expression of Bcl-2 in NSCLC cells. Our findings suggested that AP alone could induce tumor cell apoptosis, but combination therapy significantly increased apoptosis compared to treatment with AP or IR alone. Therefore, our data showed that AP may effectively increase radiosensitivity by increasing NSCLC cell apoptosis. Numerous studies have demonstrated that radiosensitization may be attributable to an increase in the percentage of radiosensitive G2/M phase cells(Raju et al. 2002). Recent studies have reported that AP is involved in cell cycle arrest at the G2/M phase via blockade of the cyclin B1/cdc2 complex and upregulation of p21 and p27 in lung cancer cells(Sheng et al. 2018). The present study showed that IR induced G2/M arrest, but, interestingly, there were more cells arrested in the G2/M phase after treatment with both IR and AP. Our observations therefore confirm that AP might increase radiosensitivity by disrupting cell cycle progression and causing cell accumulation in the G2/M phase. Moreover, IR induces DNA-DSBs and DNA damage repair(Clavreul et al. 2018). $\gamma$-H2AX is a sensitive marker of DNA-DSBs induced by radiation, 
308 is associated with the ability to repair DSBs, and is a marker of radiosensitivity(Yao et al. 2016).

309 Our study found that, in A549 and LK2 cells treated with both AP and IR, the number of $\gamma$ -

310 H2AX-positive nuclei was significantly higher than that in cells treated with IR alone. Therefore,

311 AP may enhance radiosensitivity by blocking the cell's ability to repair DNA-DSBs. Taken

312 together, this study revealed for the first time that AP may increase the radiosensitivity of

313 NSCLC cells.

314 Radioresistant cells have a more malignant phenotype through molecular and genetic alterations,

315 which allows them to survive the cytotoxic effects of IR(Bezjak et al. 2015; Yom et al. 2015).

316 However, the mechanism underlying radioresistance in NSCLC cells remains unclear. An

317 increasing number of studies have confirmed that inhibiting the AKT and ERK pathways could

318 increase the radiosensitivity of tumor cells in vivo and in vitro(Fumarola et al. 2014;

319 Leszczynska et al. 2015). In our previous study, we found that radioresistant NSCLC cells had

320 activated AKT and ERK and that downregulation of p-AKT and p-ERK could enhance cell

321 radiosensitivity(Sun et al. 2019). Additionally, it has been reported that the PI3K/AKT pathway

322 is involved in blocking apoptosis in lung cancer cell lines; p-AKT increases radioresistance by

323 inhibiting the pro-apoptotic proteins BAD, BAX, and caspase-9(Toulany \& Rodemann 2015). In

324 addition, the excessive activation of AKT accelerates IR-induced DNA-DSB repair and promotes

325 cell survival post-IR. After DNA damage, DNA-dependent protein kinase is phosphorylated by

326 AKT and accumulates at the damaged site to reinforce the efficiency of DSB repair, which is

327 involved in the mechanism of radioresistance(Toulany et al. 2012). Moreover, ERK-induced

328 radioresistance may inhibit apoptosis by suppressing IR-induced damage to the mitochondrial

329 membrane and increasing the expression of DNA repair proteins(Shonai et al. 2002). Another

330 mechanism by which ERK induces radioresistance is through P90RSK, the downstream effector

331 of ERK, which promotes the expression of a variety of anti-apoptotic proteins by

332 phosphorylating transcription factors(Riccio et al. 1999). Several studies have reported that AP

333 significantly potentiates radiosensitization by promoting apoptosis and inducing cell cycle arrest

334 at the G2/M phase by inhibiting the AKT and ERK pathways, including in cholangiocarcinoma

335 and hepatocellular carcinoma(Huang et al. 2018; Yang \& Qin 2018). In the present study, we

336 observed that IR could activate the AKT and ERK pathways, but AP effectively inhibited the

337 phosphorylation of AKT and ERK. Therefore, AP may increase radiosensitivity by suppressing

338 the activation of AKT and ERK in NSCLC cells. The possible therapeutic benefits of AP in

339 combination with radiation should be further evaluated.

340

341

\section{Conclusions}

343 In summary, our study demonstrates that AP enhances the radiosensitivity of NSCLC cells. This

344 occurs by reducing cell proliferation, inducing apoptosis and cell cycle arrest in the G2/M phase,

345 inhibiting DNA-DSB repair, and downregulating AKT and ERK. To our knowledge, this is the first study to demonstrate a novel role of AP as a radiosensitizer in NSCLC. Our findings may

347 provide clinical guidance for improving radiotherapy efficiency in patients with NSCLC. 
348 However, whether AP combined with IR is effective for clinical use remains unknown.

349 Therefore, the optimal dose of AP requires further study.

350

351

352

\section{Acknowledgements}

353

354

355

356

357

358

359

360

361

362

363

364

365

366

367

368

369

370

371

372

373

374

375

376

377

378

379

380

381

382

383

384

385

386

387

388

389

390

391

392

393

394

395

\section{References}

Bezjak A, Temin S, Franklin G, Giaccone G, Govindan R, Johnson ML, Rimner A, Schneider BJ, Strawn J, and Azzoli CG. 2015. Definitive and Adjuvant Radiotherapy in Locally Advanced Non-Small-Cell Lung Cancer: American Society of Clinical Oncology Clinical Practice Guideline Endorsement of the American Society for Radiation Oncology Evidence-Based Clinical Practice Guideline. J Clin Oncol 33:2100-2105. 10.1200/JCO.2014.59.2360

Cascone T, Xu L, Lin HY, Liu W, Tran HT, Liu Y, Howells K, Haddad V, Hanrahan E, Nilsson MB, Cortez MA, Giri U, Kadara H, Saigal B, Park YY, Peng W, Lee JS, Ryan AJ, Juergensmeier JM, Herbst RS, Wang J, Langley RR, Wistuba, II, Lee JJ, and Heymach JV. 2017. The HGF/c-MET Pathway Is a Driver and Biomarker of VEGFR-inhibitor Resistance and Vascular Remodeling in Non-Small Cell Lung Cancer. Clin Cancer Res 23:5489-5501. 10.1158/1078-0432.CCR-16-3216

Chatterjee S, Heukamp LC, Siobal M, Schottle J, Wieczorek C, Peifer M, Frasca D, Koker M, Konig K, Meder L, Rauh D, Buettner R, Wolf J, Brekken RA, Neumaier B, Christofori G, Thomas RK, and Ullrich RT. 2013. Tumor VEGF:VEGFR2 autocrine feed-forward loop triggers angiogenesis in lung cancer. J Clin Invest 123:1732-1740. 10.1172/JCl65385

Chen LT, Oh DY, Ryu MH, Yeh KH, Yeo W, Carlesi R, Cheng R, Kim J, Orlando M, and Kang YK. 2017. Anti-angiogenic Therapy in Patients with Advanced Gastric and Gastroesophageal Junction Cancer: A Systematic Review. Cancer Res Treat 49:851-868. 10.4143/crt.2016.176

Chen S, Yu W, Zhang K, and Liu W. 2018. Comparison of the efficacy and safety of Transarterial chemoembolization with and without Apatinib for the treatment of BCLC stage C hepatocellular carcinoma. BMC Cancer 18:1131. 10.1186/s12885-018-5081-3

Clavreul A, Roger E, Pourbaghi-Masouleh M, Lemaire L, Tetaud C, and Menei P. 2018. Development and characterization of sorafenib-loaded lipid nanocapsules for the treatment of glioblastoma. Drug Deliv 25:1756-1765. 10.1080/10717544.2018.1507061

Feng $\mathrm{H}$, Cheng X, Kuang J, Chen L, Yuen S, Shi M, Liang J, Shen B, Jin Z, Yan J, and Qiu W. 2018. Apatinib-induced protective autophagy and apoptosis through the AKT-mTOR pathway in anaplastic thyroid cancer. Cell Death Dis 9:1030. 10.1038/s41419-018-10543

Fumarola C, Bonelli MA, Petronini PG, and Alfieri RR. 2014. Targeting PI3K/AKT/mTOR pathway in non small cell lung cancer. Biochem Pharmacol 90:197-207. 10.1016/j.bcp.2014.05.011

Han ZQ, Liao H, Shi F, Chen XP, Hu HC, Tian MQ, Wang LH, and Ying S. 2017. Inhibition of cyclooxygenase-2 sensitizes lung cancer cells to radiation-induced apoptosis. Oncol Lett 14:5959-5965. 10.3892/ol.2017.6940

Han ZQ, Liao H, Shi F, Chen XP, Hu HC, Tian MQ, Wang LH, and Ying S. 2019. Erratum: Inhibition of cyclooxygenase-2 sensitizes lung cancer cells to radiation-induced apoptosis. Oncol Lett 17:5839-5840. 10.3892/ol.2019.10268

Hanahan D, and Weinberg RA. 2011. Hallmarks of cancer: the next generation. Cell 144:646674. 10.1016/j.cell.2011.02.013

Hein AL, Ouellette MM, and Yan Y. 2014. Radiation-induced signaling pathways that promote cancer cell survival (review). Int J Oncol 45:1813-1819. 10.3892/ijo.2014.2614

Peer] reviewing PDF | (2021:05:61005:1:1:NEW 30 Aug 2021) 
396

397

398

399

400

401

402

403

404

405

406

407

408

409

410

411

412

413

414

415

416

417

418

419

420

421

422

423

424

425

426

427

428

429

430

431

432

433

434

435

436

437

438

439

440

441

442

443

444

445

446

Hu C, Zhu P, Xia Y, Hui K, Wang M, and Jiang X. 2018. Role of the NRP-1-mediated VEGFR2independent pathway on radiation sensitivity of non-small cell lung cancer cells. $J$ Cancer Res Clin Oncol 144:1329-1337. 10.1007/s00432-018-2667-8

Hu C, Zhuang W, Qiao Y, Liu B, Liu L, Hui K, and Jiang X. 2019. Effects of combined inhibition of STAT3 and VEGFR2 pathways on the radiosensitivity of non-small-cell lung cancer cells. Onco Targets Ther 12:933-944. 10.2147/OTT.S186559

Hu X, Zhang J, Xu B, Jiang Z, Ragaz J, Tong Z, Zhang Q, Wang X, Feng J, Pang D, Fan M, Li J, Wang B, Wang Z, Zhang Q, Sun S, and Liao C. 2014. Multicenter phase II study of apatinib, a novel VEGFR inhibitor in heavily pretreated patients with metastatic triplenegative breast cancer. Int J Cancer 135:1961-1969. 10.1002/ijc.28829

Huang M, Huang B, Li G, and Zeng S. 2018. Apatinib affect VEGF-mediated cell proliferation, migration, invasion via blocking VEGFR2/RAF/MEK/ERK and PI3K/AKT pathways in cholangiocarcinoma cell. BMC Gastroenterol 18:169. 10.1186/s12876-018-0870-3

Jain RK. 2005. Normalization of tumor vasculature: an emerging concept in antiangiogenic therapy. Science 307:58-62. 10.1126/science.1104819

Jain RK. 2013. Normalizing tumor microenvironment to treat cancer: bench to bedside to biomarkers. J Clin Oncol 31:2205-2218. 10.1200/JCO.2012.46.3653

Kim SY, Jeong EH, Lee TG, Kim HR, and Kim CH. 2021. The Combination of Trametinib, a MEK Inhibitor, and Temsirolimus, an mTOR Inhibitor, Radiosensitizes Lung Cancer Cells. Anticancer Res 41:2885-2894. 10.21873/anticanres.15070

Knizetova P, Ehrmann J, Hlobilkova A, Vancova I, Kalita O, Kolar Z, and Bartek J. 2008. Autocrine regulation of glioblastoma cell cycle progression, viability and radioresistance through the VEGF-VEGFR2 (KDR) interplay. Cell Cycle 7:2553-2561. 10.4161/cc.7.16.6442

Leszczynska KB, Foskolou IP, Abraham AG, Anbalagan S, Tellier C, Haider S, Span PN, O'Neill EE, Buffa FM, and Hammond EM. 2015. Hypoxia-induced p53 modulates both apoptosis and radiosensitivity via AKT. J Clin Invest 125:2385-2398. 10.1172/JCI80402

Lewis CD, Singh AK, Hsu FF, Thotala D, Hallahan DE, and Kapoor V. 2021. Targeting a Radiosensitizing Antibody-Drug Conjugate to a Radiation-Inducible Antigen. Clin Cancer Res 27:3224-3233. 10.1158/1078-0432.CCR-20-1725

Li Y, Sun C, Tan Y, Zhang H, Li Y, and Zou H. 2021. ITGB1 enhances the Radioresistance of human Non-small Cell Lung Cancer Cells by modulating the DNA damage response and YAP1-induced Epithelial-mesenchymal Transition. Int $J$ Biol Sci 17:635-650. 10.7150/ijbs.52319

Liang LJ, Hu CX, Wen YX, Geng XW, Chen T, Gu GQ, Wang L, Xia YY, Liu Y, Fei JY, Dong J, Zhao FH, Ahongjiang Y, Hui KY, and Jiang XD. 2020. Apatinib Combined with Local Irradiation Leads to Systemic Tumor Control via Reversal of Immunosuppressive Tumor Microenvironment in Lung Cancer. Cancer Res Treat 52:406-418. 10.4143/crt.2019.296

Liao J, Jin H, Li S, Xu L, Peng Z, Wei G, Long J, Guo Y, Kuang M, Zhou Q, and Peng S. 2019. Apatinib potentiates irradiation effect via suppressing PI3K/AKT signaling pathway in hepatocellular carcinoma. J Exp Clin Cancer Res 38:454. 10.1186/s13046-019-1419-1

Liu L, Qiao Y, Hu C, Liu Y, Xia Y, Wang L, Liu B, Chen H, and Jiang X. 2016. Endostatin exerts radiosensitizing effect in non-small cell lung cancer cells by inhibiting VEGFR2 expression. Clin Transl Oncol 18:18-26. 10.1007/s12094-015-1319-6

Liu W, Zhang J, Yao X, Jiang C, Ni P, Cheng L, Liu J, Ni S, Chen Q, Li Q, Zhou K, Wang G, and Zhou F. 2018. Bevacizumab-enhanced antitumor effect of 5-fluorouracil via upregulation of thymidine phosphorylase through vascular endothelial growth factor A/vascular endothelial growth factor receptor 2-specificity protein 1 pathway. Cancer Sci 109:32943304. 10.1111/cas.13779

Liu ZL, Jin BJ, Cheng CG, Zhang FX, Wang SW, Wang Y, and Wu B. 2017. Apatinib resensitizes cisplatin-resistant non-small cell lung carcinoma A549 cell through reversing multidrug resistance and suppressing ERK signaling pathway. Eur Rev Med Pharmacol Sci

Peer) reviewing PDF | (2021:05:61005:1:1:NEW 30 Aug 2021) 
447

448

449

450

451

452

453

454

455

456

457

458

459

460

461

462

463

464

465

466

467

468

469

470

471

472

473

474

475

476

477

478

479

480

481

482

483

484

485

486

487

488

489

490

491

492

493

494

495

496

497

21:5370-5377. 10.26355/eurrev_201712_13922

Longo R, and Gasparini G. 2007. Challenges for patient selection with VEGF inhibitors. Cancer Chemother Pharmacol 60:151-170. 10.1007/s00280-006-0403-6

Lu W, Ke H, Qianshan D, Zhen W, Guoan X, and Honggang Y. 2017. Apatinib has anti-tumor effects and induces autophagy in colon cancer cells. Iran J Basic Med Sci 20:990-995. 10.22038/IJBMS.2017.9263

Ohri N, Dawson LA, Krishnan S, Seong J, Cheng JC, Sarin SK, Kinkhabwala M, Ahmed MM, Vikram B, Coleman CN, and Guha C. 2016. Radiotherapy for Hepatocellular Carcinoma: New Indications and Directions for Future Study. J Natl Cancer Inst 108. 10.1093/jnci/djw133

Peng QX, Han YW, Zhang YL, Hu J, Fan J, Fu SZ, Xu S, and Wan Q. 2017. Apatinib inhibits VEGFR-2 and angiogenesis in an in vivo murine model of nasopharyngeal carcinoma. Oncotarget 8:52813-52822. 10.18632/oncotarget.17264

Procaccio L, Damuzzo V, Di Sarra F, Russi A, Todino F, Dadduzio V, Bergamo F, Prete AA, Lonardi S, Prenen H, Palozzo AC, and Loupakis F. 2019. Safety and Tolerability of AntiAngiogenic Protein Kinase Inhibitors and Vascular-Disrupting Agents in Cancer: Focus on Gastrointestinal Malignancies. Drug Saf 42:159-179. 10.1007/s40264-018-0776-6

Raju U, Nakata E, Yang P, Newman RA, Ang KK, and Milas L. 2002. In vitro enhancement of tumor cell radiosensitivity by a selective inhibitor of cyclooxygenase-2 enzyme: mechanistic considerations. Int J Radiat Oncol Biol Phys 54:886-894. 10.1016/s03603016(02)03023-7

Riccio A, Ahn S, Davenport CM, Blendy JA, and Ginty DD. 1999. Mediation by a CREB family transcription factor of NGF-dependent survival of sympathetic neurons. Science 286:2358-2361. 10.1126/science.286.5448.2358

Schrank Z, Chhabra G, Lin L, Iderzorig T, Osude C, Khan N, Kuckovic A, Singh S, Miller RJ, and Puri N. 2018. Current Molecular-Targeted Therapies in NSCLC and Their Mechanism of Resistance. Cancers (Basel) 10. 10.3390/cancers10070224

Seidlitz A, Beuthien-Baumann B, Lock S, Jentsch C, Platzek I, Zophel K, Linge A, Kotzerke J, Petr J, van den Hoff J, Steinbach J, Krex D, Schmitz-Schackert G, Falk M, Baumann M, and Krause M. 2020. Final results of the prospective biomarker trial PETra: [(11)C]-METaccumulation in postoperative PET/MRI predicts outcome after radiochemotherapy in glioblastoma. Clin Cancer Res. 10.1158/1078-0432.CCR-20-1775

Sheng J, Zhao Q, Zhao J, Zhang W, Sun Y, Qin P, Lv Y, Bai L, Yang Q, Chen L, Qi Y, Zhang G, Zhang L, Gu C, Deng X, Liu H, Meng S, Gu H, Liu Q, Coulson JM, Li X, Sun B, and Wang Y. 2018. SRSF1 modulates PTPMT1 alternative splicing to regulate lung cancer cell radioresistance. EBioMedicine 38:113-126. 10.1016/j.ebiom.2018.11.007

Shonai T, Adachi M, Sakata K, Takekawa M, Endo T, Imai K, and Hareyama M. 2002. MEK/ERK pathway protects ionizing radiation-induced loss of mitochondrial membrane potential and cell death in lymphocytic leukemia cells. Cell Death Differ 9:963-971. 10.1038/sj.cdd.4401050

Sun C, Li Y, Tan Y, Zhang H, Liang Y, Zeng J, Yu J, and Zou H. 2019. A novel role for NFIA in restoring radiosensitivity in radioresistant NSCLC cells by downregulating the AKT and ERK pathways. Biochem Biophys Res Commun 515:558-564. 10.1016/j.bbrc.2019.06.011

Sung H, Ferlay J, Siegel RL, Laversanne M, Soerjomataram I, Jemal A, and Bray F. 2021. Global Cancer Statistics 2020: GLOBOCAN Estimates of Incidence and Mortality Worldwide for 36 Cancers in 185 Countries. CA Cancer J Clin 71:209-249. 10.3322/caac.21660

Tian S, Quan H, Xie C, Guo H, Lu F, Xu Y, Li J, and Lou L. 2011. YN968D1 is a novel and selective inhibitor of vascular endothelial growth factor receptor-2 tyrosine kinase with potent activity in vitro and in vivo. Cancer Sci 102:1374-1380. 10.1111/j.13497006.2011.01939.x

Peer] reviewing PDF | (2021:05:61005:1:1:NEW 30 Aug 2021) 
498

499

500

501

502

503

504

505

506

507

508

509

510

511

512

513

514

515

516

517

518

519

520

521

522

523

524

525

526

527

528

529

Toulany M, Lee KJ, Fattah KR, Lin YF, Fehrenbacher B, Schaller M, Chen BP, Chen DJ, and Rodemann HP. 2012. Akt promotes post-irradiation survival of human tumor cells through initiation, progression, and termination of DNA-PKcs-dependent DNA double-strand break repair. Mol Cancer Res 10:945-957. 10.1158/1541-7786.MCR-11-0592

Toulany M, and Rodemann HP. 2015. Phosphatidylinositol 3-kinase/Akt signaling as a key mediator of tumor cell responsiveness to radiation. Semin Cancer Biol 35:180-190. 10.1016/j.semcancer.2015.07.003

Wieczorek SA, Breitenbuecher F, Soni A, Paul-Konietzko K, Ziegler S, Sak A, lliakis G, and Schuler M. 2017. Deregulated BCL-2 family proteins impact on repair of DNA doublestrand breaks and are targets to overcome radioresistance in lung cancer. J Cancer Res Clin Oncol 143:1733-1744. 10.1007/s00432-017-2427-1

Wrona A, Dziadziuszko R, and Jassem J. 2021. Combining radiotherapy with targeted therapies in non-small cell lung cancer: focus on anti-EGFR, anti-ALK and anti-angiogenic agents. Transl Lung Cancer Res 10:2032-2047. 10.21037/tlcr-20-552

Xiong L, Tan B, Lei X, Zhang B, Li W, Liu D, and Xia T. 2021. SIRT6 through PI3K/Akt/mTOR signaling pathway to enhance radiosensitivity of non-Small cell lung cancer and inhibit tumor progression. IUBMB Life. 10.1002/iub.2511

Yang C, and Qin S. 2018. Apatinib targets both tumor and endothelial cells in hepatocellular carcinoma. Cancer Med 7:4570-4583. 10.1002/cam4.1664

Yao YH, Cui Y, Qiu XN, Zhang LZ, Zhang W, Li H, and Yu JM. 2016. Attenuated LKB1-SIK1 signaling promotes epithelial-mesenchymal transition and radioresistance of non-small cell lung cancer cells. Chin J Cancer 35:50. 10.1186/s40880-016-0113-3

Yom SS, Diehn M, and Raben D. 2015. Molecular determinants of radiation response in nonsmall cell lung cancer. Semin Radiat Oncol 25:67-77. 10.1016/j.semradonc.2014.12.007

Zhao C, Zhang Q, and Qiao W. 2017a. Significant efficacy and well safety of apatinib combined with radiotherapy in NSCLC: Case report. Medicine (Baltimore) 96:e9276. 10.1097/MD.0000000000009276

Zhao F, Tian W, Zeng M, Xia J, Hu H, Hao X, Han L, Liu H, He Y, Zhu X, Liang L, Ao R, Wei M, Deng L, and Wei Y. 2017b. Apatinib alone or combined with radiotherapy in metastatic prostate cancer: Results from a pilot, multicenter study. Oncotarget 8:110774-110784. 10.18632/oncotarget.22719

Peer) reviewing PDF | (2021:05:61005:1:1:NEW 30 Aug 2021) 


\section{Table $\mathbf{1}$ (on next page)}

Radiation biological parademeter 
Table 1 Radiation biological parameter

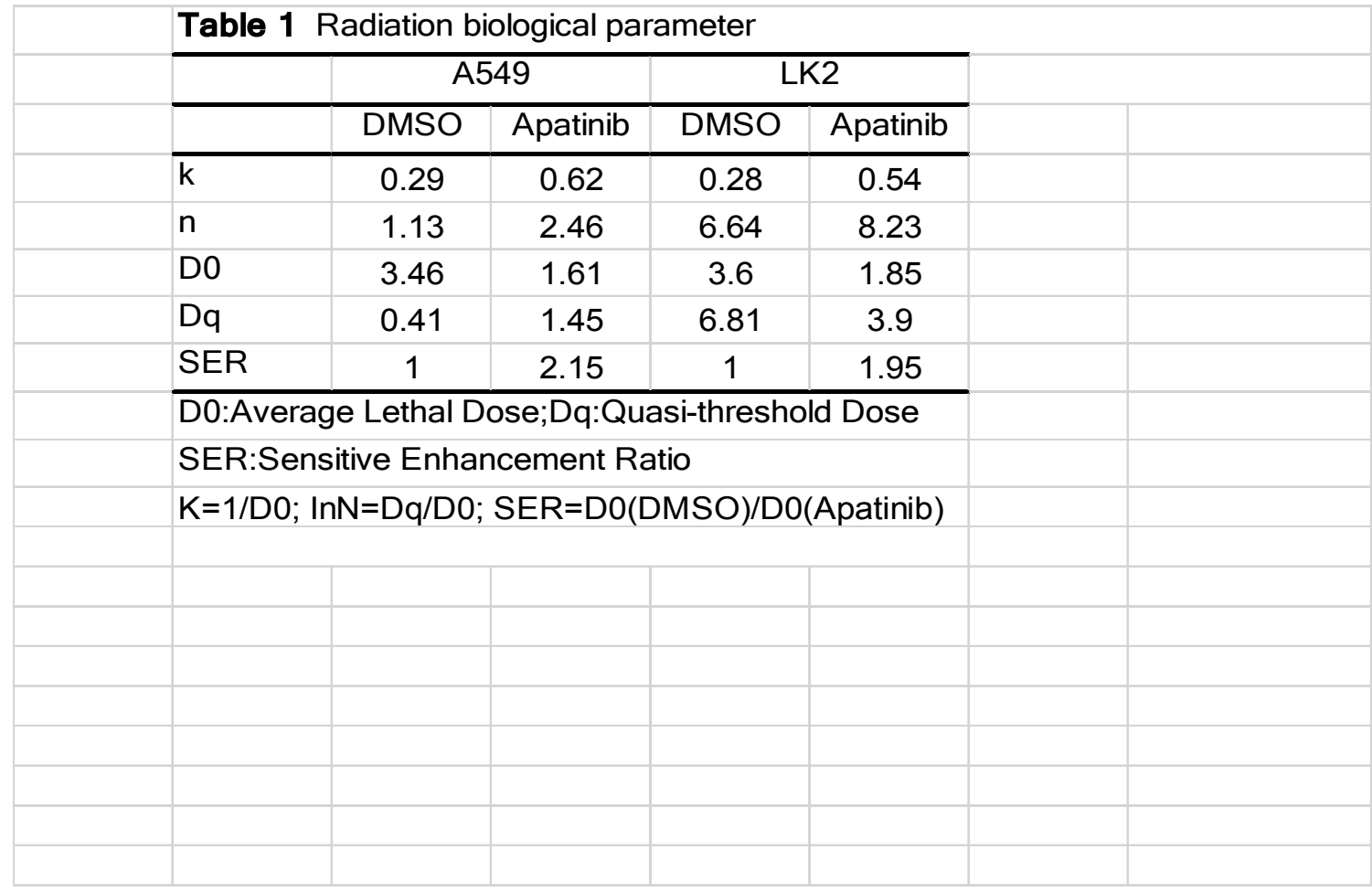


Figure 1

Fig.1 Expression of VEFGR2 in NSCLC cells

A . Differential expression of VEGFR2 protein in different non-small cell lung cancer (NSCLC) cell lines by Western blotting. B. Quantitative analysis of VEGFR2 mRNA by qRT-PCR. C and E. Apatinib inhibited cell proliferation in a dose and time dependent manner in A549 and LK2 respectively. D and F. The IC50 value of apatinib after treatment for $72 \mathrm{~h}$ in A549 and LK2 respectively. Each data point represents the mean \pm SD from three independent experiments. $* p<0.05$. $* * p<0.01$. 
A

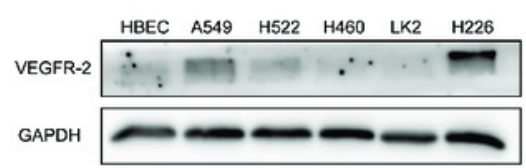

C

A549

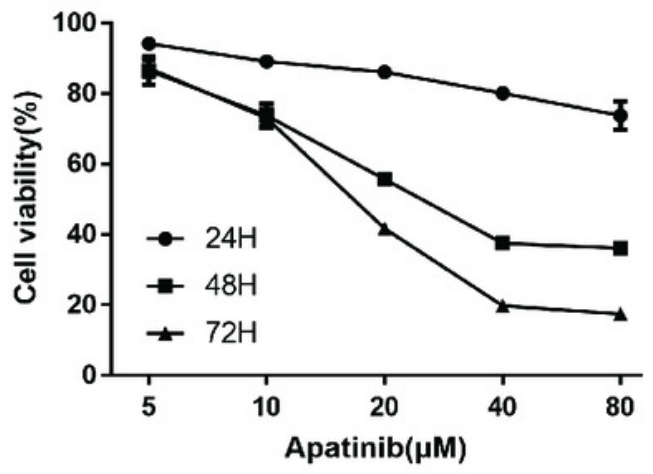

E

LK2

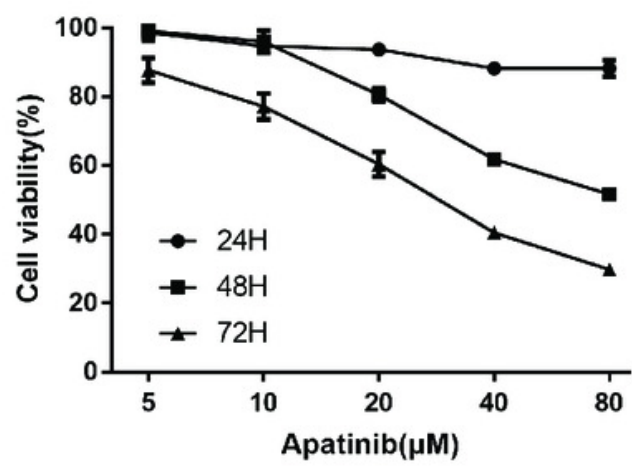

B

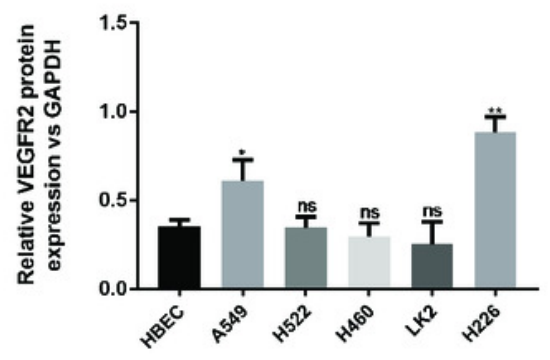

D

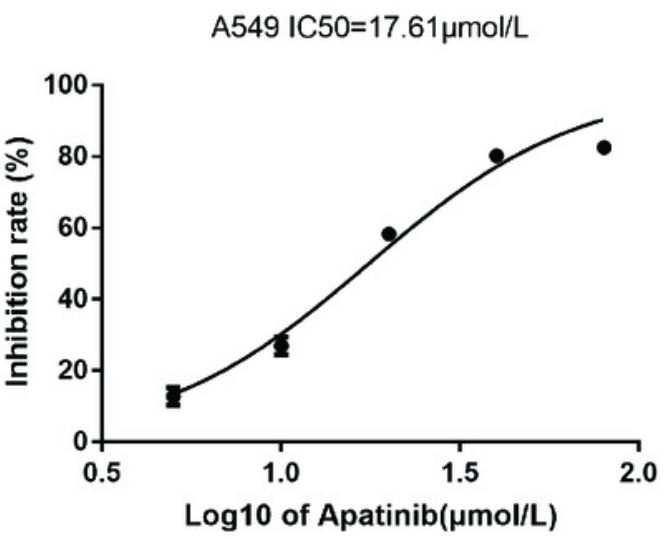

F

LK2 IC50=30.73 $\mu \mathrm{mol} / \mathrm{L}$

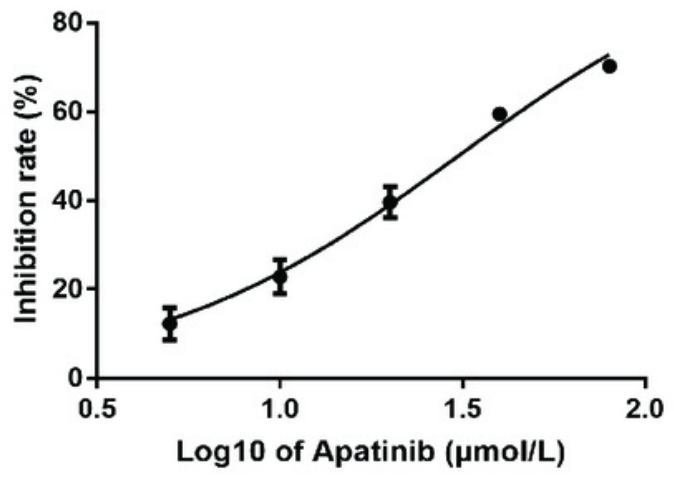




\section{Figure 2}

Fig.2 Apatinib inhibited the proliferation and enhanced radiosensitivity of NSCLC cells.

A and B. Cell proliferation was measured using CCK8. C and D. Apatinib combined irradiation significantly reduced the colony formation ability of A549 and LK2 cells compared with control group, X-ray or apatinib group. Survival fractions obtained by colony formation assays in A549 cells and LK2 cells following treatment with 0, 2, 4, 6, and 8Gy (right). Each data point represents the mean $\pm \mathrm{SD}$ from three independent experiments. $* p<0.05$. $* *<$ 0.01 . 
A

A549

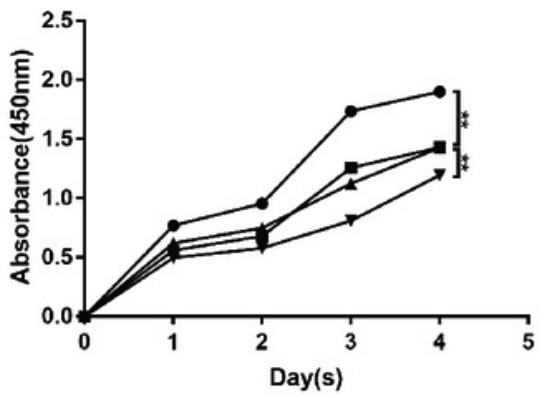

B

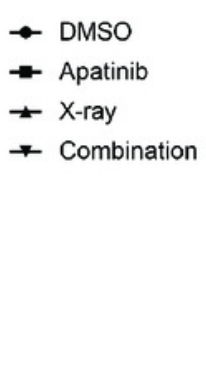

LK2

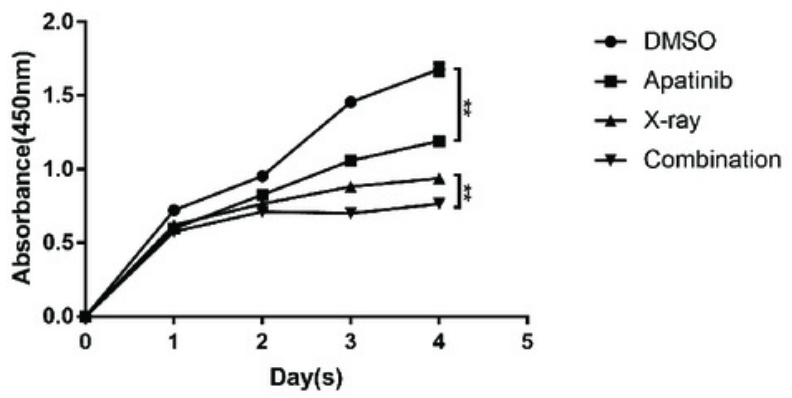

C

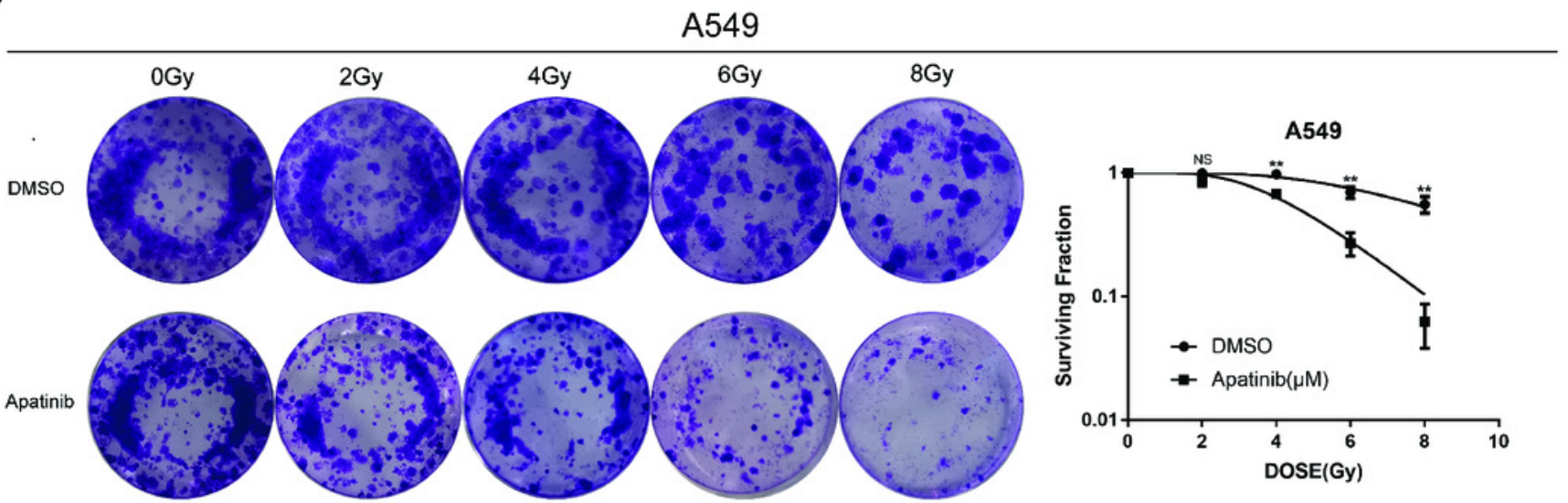

D

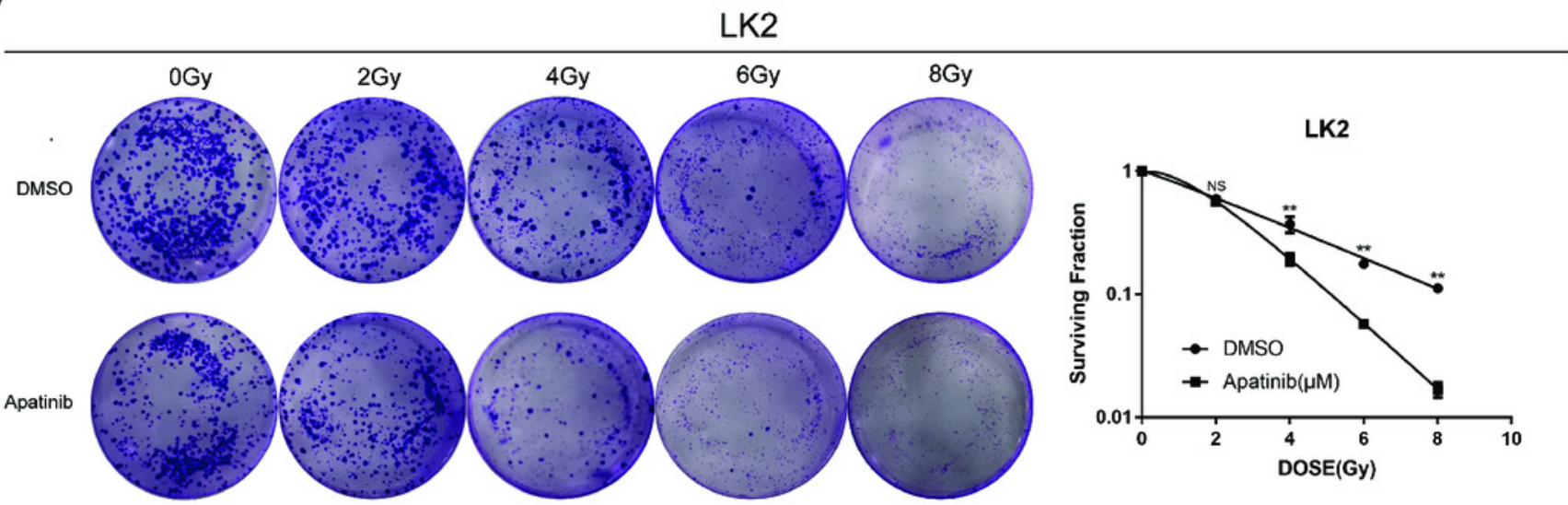




\section{Figure 3}

Fig. 3 Apatinib promoted radiation-induced apoptosis and induced G2/M phase arrest.

A. Analysis of cell apoptosis by Annexin-V FITC/PI double staining in A549 and Lk2 cells following treatment with control group, apatinib, X-ray, and combination. B. Cell cycle analysis in A549 and Lk2 cells following treatment with control group, apatinib, X-ray, and combination. Each data point represents the mean \pm SD from three independent experiments. $* p<0.05$. ${ }^{* *} p<0.01$. *** $p<0.001$. 


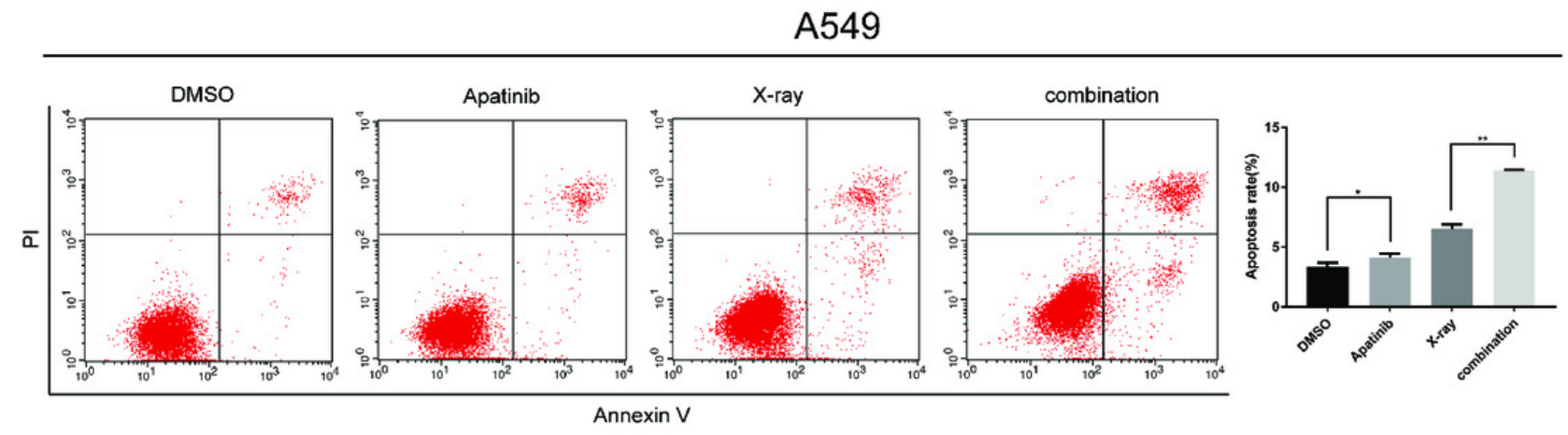

B

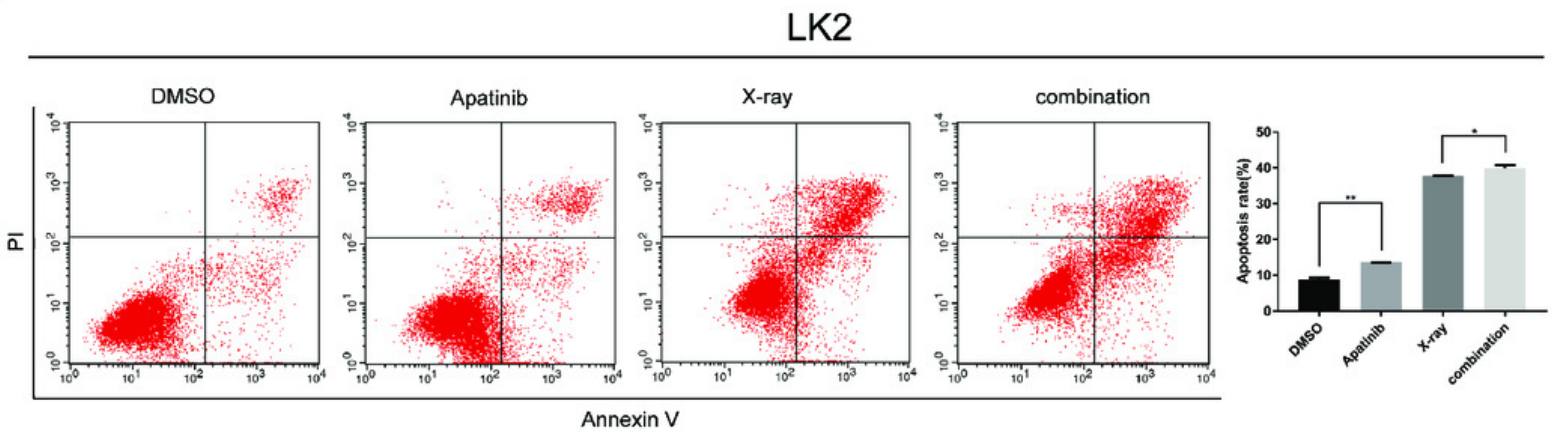

C

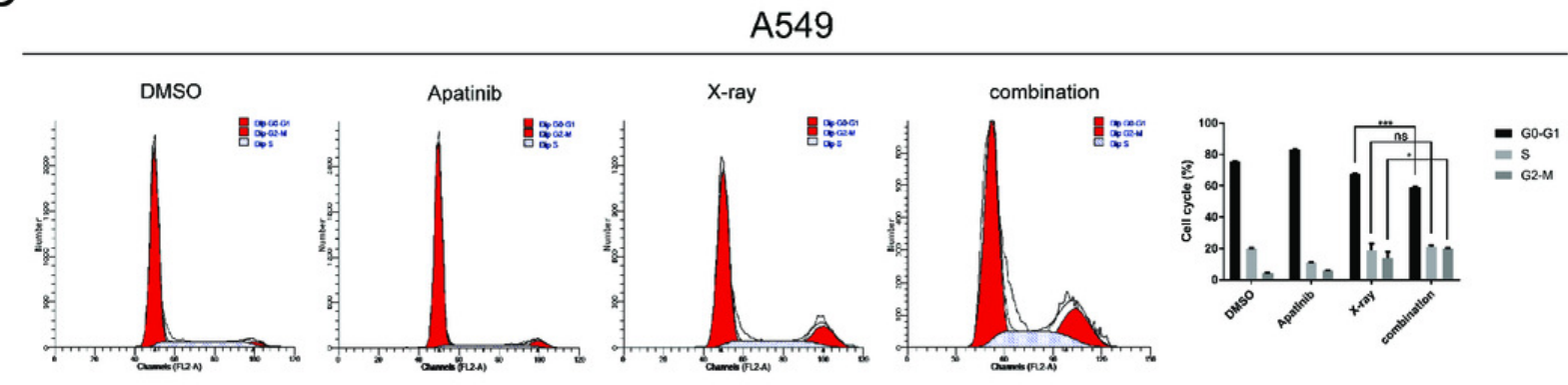

D

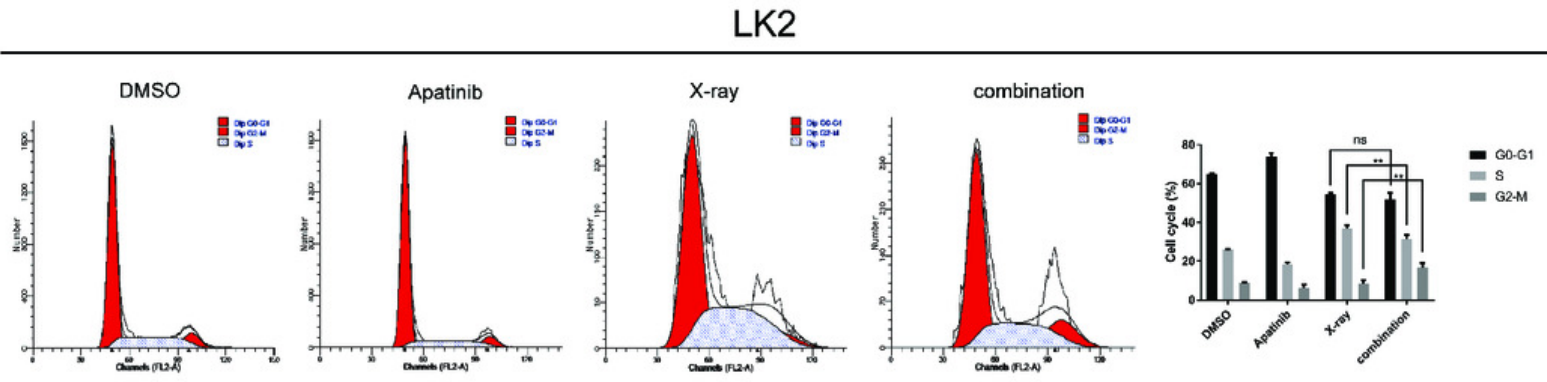




\section{Figure 4}

Fig.4 Apatinib impaired the ability of radiation-induced DNA-DSBs repair.

A-B. The representative images of g-H2AX-positive cells in A549 and LK2 cells treated with $\mathrm{IR}(8 \mathrm{~Gy})$ or in combination with apatinib at $4 \mathrm{~h} . \mathrm{\gamma}-\mathrm{H} 2 \mathrm{AX}$ signal in red, nuclear counterstaining with 4',6-diamidino-2-phenylindole in blue. Scale bar: $50 \mu \mathrm{m}$. Values represent the average of three independent experiments (right). $* p<0.05$. $* * p<0.01$. ${ }^{* * *} p<0.001$.

A
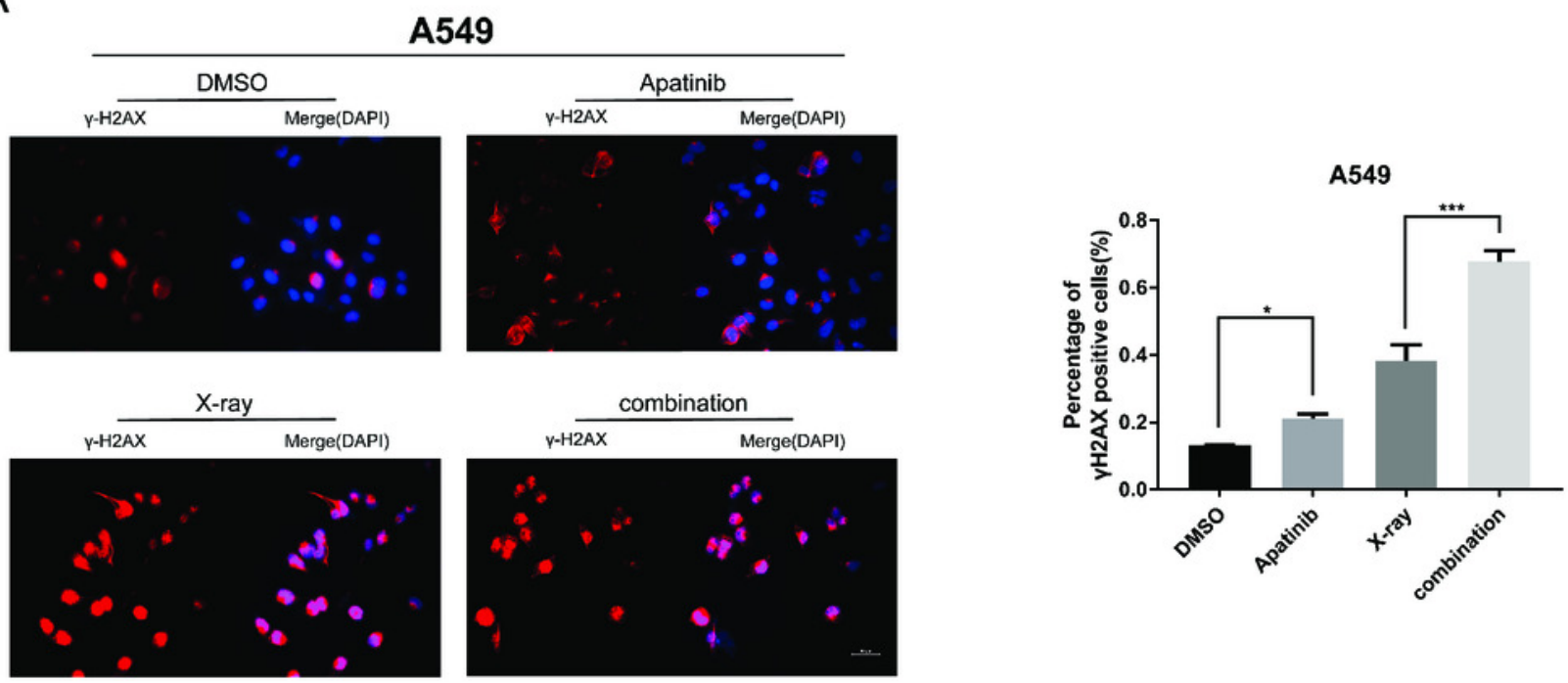

B
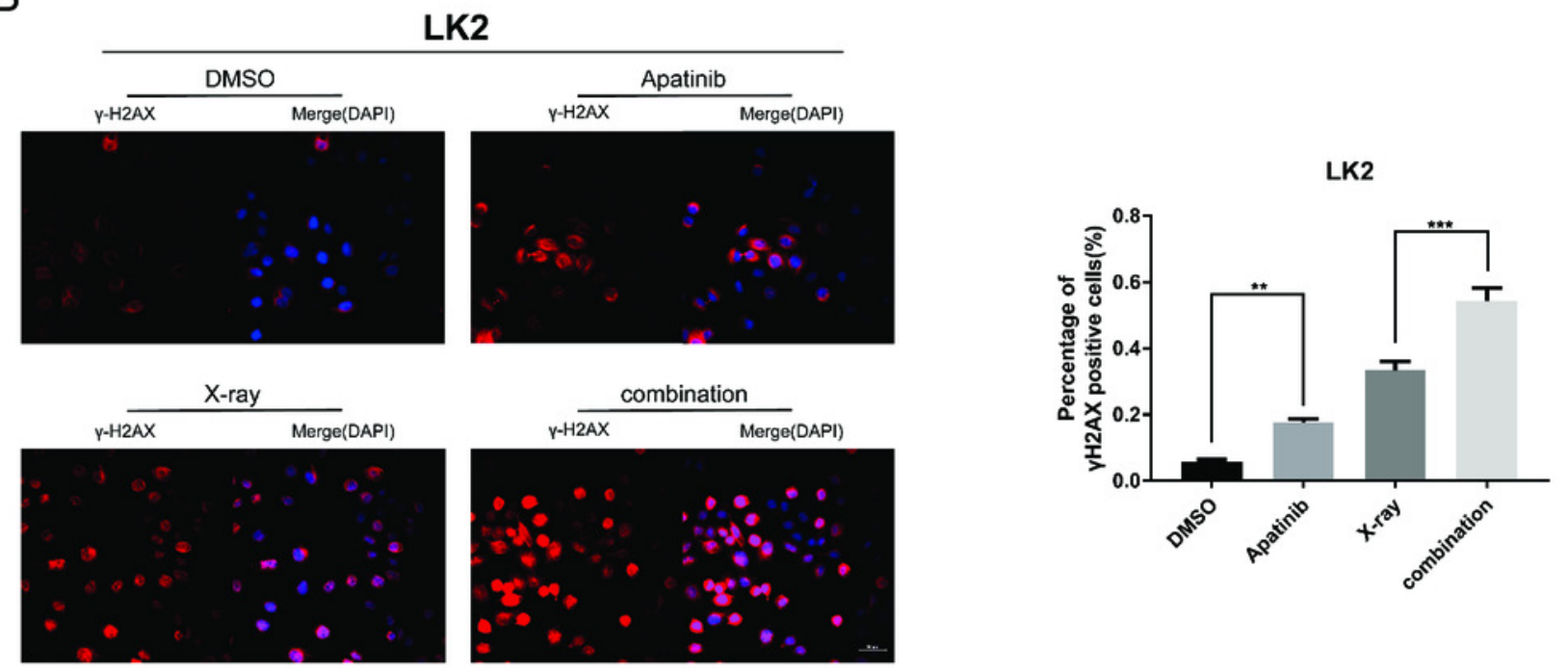
Figure 5

Fig.5 Apatinib reduced phosphorylation of AKT and ERK.

A-B. Protein levels of ERK(p-ERK) and AKT(p-AKT) were detected by western blotting in A549 and LK2 cells. Values represent the average of three independent experiments (right). ${ }^{*} p<$ 0.05. $* * p<0.01$.

A

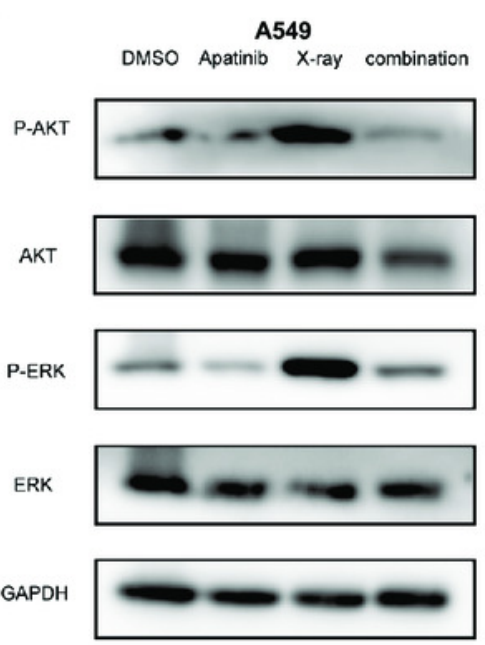

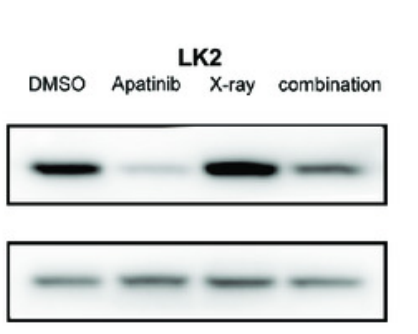
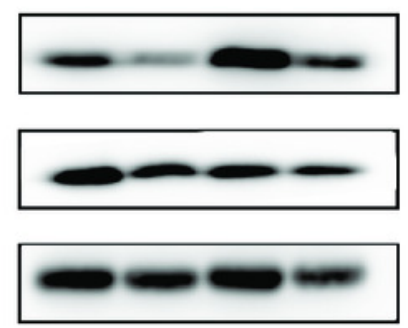

B
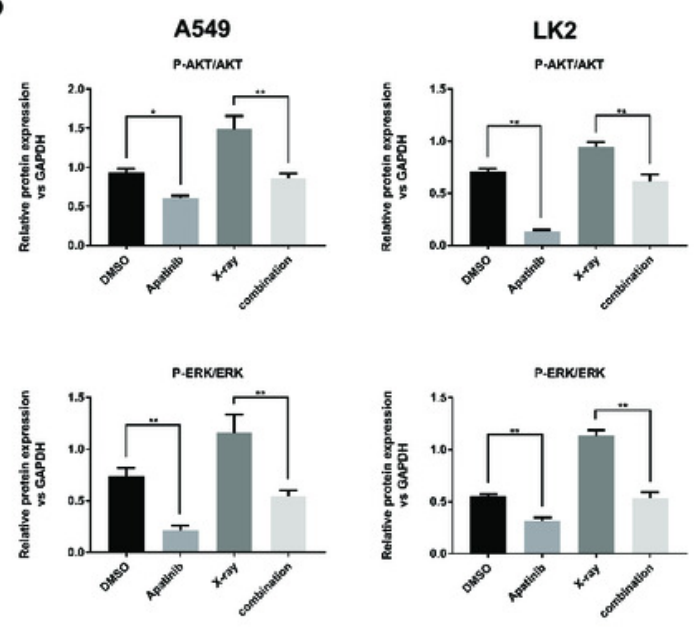